\title{
The Thermal and Crystallization Studies of Luffa Fiber Reinforced Poly Lactic Acid Composites
}

\author{
Chhatrapati Parida ${ }^{*}$, Sarat Kumar Dash ${ }^{2}$, Pinaki Chaterjee ${ }^{3}$ \\ ${ }^{1}$ Department of Physics, Orissa University of Agriculture and Technology, Bhubaneswar, India \\ ${ }^{2}$ Department of Education in Science and Mathematics, National Council of Educational Research and Training, \\ Bhubaneswar, India \\ ${ }^{3}$ Laboratory for Advanced Research in Polymeric Materials (LARPM), CIPET, Bhubaneswar, India \\ Email: "sivaji_1976@yahoo.co.in
}

Received 25 September 2016; accepted 28 December 2015; published 31 December 2015

Copyright (C) 2016 by authors and Scientific Research Publishing Inc.

This work is licensed under the Creative Commons Attribution International License (CC BY).

http://creativecommons.org/licenses/by/4.0/

(c) (i) Open Access

\begin{abstract}
Poly lactic acid (PLA) - chemically treated fiber of Luffa cylindrica (LC) composites were fabricated by micro-compounding followed by injection molding method. Before reinforcement, LC fibers were exposed to chemical treatment like alkali treatment, bleaching and acid hydrolysis. The chemically treated LC fibers were then modified with Ca salts to explore their uses in bio medical industries. Thermal stability of chemically extracted cellulose fibers of LC and PLA composites reinforced with $2 \mathrm{wt} \%, 5 \mathrm{wt} \%$ and $10 \mathrm{wt} \% \mathrm{LC}$ fibers were studied by thermo gravimetric analysis (TGA) in the temperature range from $30^{\circ} \mathrm{C}$ to $700^{\circ} \mathrm{C}$. Better interfacial bonding between fiber and matrix was evidenced by increased thermal stability of composites due to incorporation of fiber. Crystallization and melting behavior of PLA composites were studied in the temperature range from $30^{\circ} \mathrm{C}$ to $170^{\circ} \mathrm{C}$ at heating rate of $10^{\circ} /$ minute. The crystallization temperature and crystallization enthalpy increased up to $2 \mathrm{wt} \%$ of LC fiber content and gradually decreased with further increase of fiber content in the composites. Double melting peaks were observed for all composite samples and possible explanations were suggested on the basis of different crystalline structure of PLA and melt crystallization phenomena.
\end{abstract}

\section{Keywords}

Bio-Composite, Crystallization, Nucleation, Multiple Melting

\footnotetext{
${ }^{*}$ Corresponding author.
}

How to cite this paper: Parida, C., Dash, S.K. and Chaterjee, P. (2016) The Thermal and Crystallization Studies of Luffa Fiber Reinforced Poly Lactic Acid Composites. Open Journal of Composite Materials, 6, 1-7. 


\section{Introduction}

As the demand for the reduction of the environmental hazards is at its peak, development of materials based on bio degradable polymers is gaining much attention. Completely biodegradable polymers like startch, poly lactic acid, poly hydroxy alkanoates etc. are currently drawing attention from various researchers across the globe [1] [2]. Poly lactic acid (PLA) is obtained by polymerization of lactic acid. Lactic acid is derived from annually renewable agricultural resources like rice, corn, wheat, sugar beet etc. During degradation, PLA degrades to lactic acid and then lactic acid breaks to carbon dioxide, water and biomass. Hence the PLA fits to the environmental cycle. The normal degradation time for petroleum based polymers like poly styrene and polyethylene are from 500 years to 1000 years while for PLA it is from months to few years with 10 years as upper limit. Due to this biodegradability nature of PLA, its composites find various applications in the field of biomedical industry such as drug delivery systems, suture implants, bone fixation devices etc. Due to increased demand, the price for production of PLA has been reduced and commercial production of PLA based composites are increasing dramatically in recent years [3] [4].

Various properties of semi crystalline polymers like PLA depend mainly on its thermal history, so that a better understanding of its thermal behavior is necessary to get a clear picture of use of these polymers in composite materials. Thermal behavior of PLA like polymers is often studied with thermogravimetric analysis (TGA) and differential scanning calorimetry (DSC). The major objective of our study is to investigate the thermal stability of PLA based composites with the addition of small amount of chemically treated fibers of LC ( $2 \mathrm{wt} \%, 5 \mathrm{wt} \%$ and $10 \mathrm{wt} \%)$. The objectives behind interpretations of DSC thermograms were to evaluate glass transition temperature, crystallization temperature and enthalpy, melting temperature and melting enthalpy. During the course of our investigation, appearance of double melting peaks in the DSC thermo grams was observed. The analysis of crystallization and double melting peak phenomena are essential for development of industrial processing and understanding of other properties of composite materials like dimensional stability, creep behavior etc. LC is commonly called sponge gourd, bath sponge or dish cloth gourd. It is a member of cucurbitaceous family and composed of $60 \%$ cellulose, $30 \%$ hemicellulose and $10 \%$ lignin [5]. LC is a well known vegetable and is available plentily as local forest product. They have so far found very little limited applications in the field of materials. The absence of a detailed study of its characteristics and properties in the scientific literature and high percentage of cellulose (60\%) make this fiber material become our topic of research. The novelty of our study is the modification of surface of LC fibers by Ca salts, before using these as reinforcement. The modification of the surface of LC fiber by Ca salts opens the possibility in using these composites in bio medical applications such as bone replacement, dental filling, bone tissue engineering, drug delivery etc. [5].

Composites using cellulose nanofiber (CNF) and PLA was fabricated using solvent casting method by Abdulkhani et al. in 2014 [6]. DSC study of composites revealed that partly amorphous CNF reinforcement during processing was changing the crystalline properties of the composites. Double melting peaks around $150.6^{\circ} \mathrm{C}$ and $156.3^{\circ} \mathrm{C}$ were detected in all composite samples. The reinforcement of CNF up to $5 \mathrm{wt} \%$ caused a slight increase in glass transition temperature and melting temperature. PLA and rice hulls composites fabricated via compression molding techniques were reported by Vineta Srebrenkaska et al. in 2014 [7]. Thermal stability of PLA based composites was decreased compared to that of neat PLA due to incorporation of rice hulls. Maximum wt loss peak for neat PLA detected from TG curve was reached at $362.9^{\circ} \mathrm{C}$ but the loss peak temperature was reduced to $343.2^{\circ} \mathrm{C}$ (almost $20^{\circ}$ less than neat PLA) when rice hulls were introduced in to the PLA matrix. Kenaf fiber-PLA composites were fabricated using melt compounding and injection molding by Seong OK Han et al. in 2012 [8]. They reported decrease of glass transition temperature and crystallization temperature with increase of fiber content in the composites. The crystallization temperature decreased from $113^{\circ} \mathrm{C}$ for neat PLA to $98^{\circ} \mathrm{C}$ for $20 \mathrm{wt} \%$ kenaf fiber reinforcement and to $92^{\circ} \mathrm{C}$ for $40 \mathrm{wt} \%$ kenaf fiber reinforcement. The single melting point observed at $150^{\circ} \mathrm{C}$ in neat PLA was shifted to low temperature upon addition of kenaf fiber and a second minor peak appeared in the range $135^{\circ} \mathrm{C}-140^{\circ} \mathrm{C}$. Both the peaks were observed to shift to lower values with introduction of more wt of fiber in the composites.

\section{Experimental}

\subsection{Materials}

Poly lactic acid (PLA) grade $4042 \mathrm{D}$ (having molecular weight $\mathrm{Mw} \sim 600,000$ ), was purchased from Nature 
Works, USA. The fruit of LC was collected from local forest area. The chemicals such as calcium chloride $\left(\mathrm{CaCl}_{2} 2 \mathrm{H}_{2} \mathrm{O}, 97 \%\right)$, di sodium hydrogen phosphate $\left(\mathrm{Na}_{2} \mathrm{HPO}_{4} 2 \mathrm{H}_{2} \mathrm{O}\right.$, 99.5\%), sodium hydroxide $(\mathrm{NaOH})$, sodium hypochlorite $(\mathrm{NaClO})$ all of AR grade were procured from $\mathrm{E}$. Merck, India.

\subsection{Chemical Treatment of LC Fiber}

The fibers of LC were cut into small pieces of length around $2 \mathrm{~cm}$ and then washed thoroughly with deionized water to remove impurities followed by oven drying at $70^{\circ} \mathrm{C}$ for 20 minutes. The dried LC fibers were subjected to chemical treatment such as treatment with alkali followed by bleaching and acid hydrolysis. For alkali treatment, the LC fibers were initially soaked in a $5 \% \mathrm{NaOH}$ solution at $80^{\circ} \mathrm{C}$ for $1 \mathrm{~h}$ and then dried at room temperature for $48 \mathrm{~h}$ followed by drying in oven at $60^{\circ} \mathrm{C}$ for $6 \mathrm{~h}$. Natural fibers are hydrophilic in nature which leads to poor adhesion with the matrix, ultimately causing weakening of bonds between fiber and matrix. In wet conditions, therefore, such composites show very poor mechanical properties. To improve interfacial bonding and to reduce moisture absorption the LC fibers were exposed to alkali treatment during which the hemicelluloses and lignin present in the fibers were eliminated. Thus the number of hydroxyl groups (-OH) present in the LC fiber is reduced leading to enhancement of hydrophobicity of fibers which is responsible to strengthen the bonding between fiber and matrix. The alkali treated LC fibers were then bleached with $2 \%$ sodium hypochlorite solution by stirring the mixture for $2 \mathrm{~h}$ at $80^{\circ} \mathrm{C}$. Bleaching is mainly done with the objective of increasing whiteness of the fibers. Finally the bleached LC fiber /water suspension was prepared and kept on an ice bath. $\mathrm{H}_{2} \mathrm{SO}_{4}$ was added slowly under continuous stirring to the suspension placed in an ice water bath, until the final concentration of $60 \%$ $\mathrm{H}_{2} \mathrm{SO}_{4}$ was reached. For removal of excess acid, the mixture was washed and centrifuged using an ultracentrifuge at $30^{\circ} \mathrm{C}$ for 20 minutes with $7000 \mathrm{rpm}$. Acid hydrolysis of LC fiber leads to the isolation of micro and nano-fibers with a high degree of crystallinity by removing the amorphous regions of the raw cellulose material. It also decreased the degree of polymerization (DP) and molecular weight of the bleached fibers [9].

\subsection{Modification of Surface of Chemically Treated LC Fiber by Ca Salts}

The dried LC fiber was immersed in $\mathrm{CaCl}_{2}$ solution for $12 \mathrm{~h}$ at room temperature of $30^{\circ} \mathrm{C}$ to deposit $\mathrm{Ca}$ on its surface. The LC fiber modified with $\mathrm{CaCl}_{2}$, were then re-immersed in $\mathrm{Na} 2 \mathrm{HPO} 4$ solution for $12 \mathrm{~h}$ at room temperature $30^{\circ} \mathrm{C}$ to deposit compounds of calcium phosphate over it [9].

\subsection{Composite Processing}

The PLA pellets and treated LC fibers were dried under vacuum at $80^{\circ} \mathrm{C}$ for $24 \mathrm{~h}$ prior to processing. The PLA pellets and chemically treated LC fiber were mixed mechanically at $100 \mathrm{rpm}$ with a micro-compounding molding equipment (DSM Micro 15 cc compounding system, DSM research, The Netherlands) at $170^{\circ} \mathrm{C}$ for $10 \mathrm{mi}-$ nutes. The extruder is equipped with a screw of length $150 \mathrm{~mm}, \mathrm{~L} / \mathrm{D}$ of 18 , and net capacity of $15 \mathrm{cc}$. The molten composite samples were transferred after extrusion through a preheated cylinder to the mini injection molder, which is pre-set with desired temperature and cooling system to obtain the desired specimen samples for further measurements and analysis. The PLA pellets and LC fibers are mixed in different wt proportion to get four composite samples B0, B1, B2 and B3. B0 is the neat PLA without any fiber. In composite samples B1, B2 and B3, the LC fibers are in the wt ratio $2 \%, 5 \%$ and $10 \%$ respectively. Sample C is the cellulose fibers extracted after various chemical treatments given to LC fiber.

\subsection{Differential Scanning Calorimeter (DSC)}

DSC thermograms were recorded for all the composite samples using a standard aluminum pan, in a differential scanning calorimeter (Q20, M/s TA instruments, USA) under nitrogen atmosphere and the heating rate was maintained at $10^{\circ} \mathrm{C} / \mathrm{min}$. Samples $(7 \mathrm{mg})$ were loaded without further treatment. The initial and final temperatures were taken as ambient and $200^{\circ} \mathrm{C}$, respectively.

\subsection{Thermo Gravimetric Analysis (TGA)}

The thermal stability of all samples was studied employing thermo gravimetric analysis (TGA; Q50, TA Instruments, USA). The samples were scanned from $30^{\circ} \mathrm{C}$ to $800^{\circ} \mathrm{C}$ at a rate of $10^{\circ} \mathrm{C} / \mathrm{min}$ under nitrogen atmosphere. 
Corresponding degradation temperatures and percentage mass loss were reported.

\section{Results and Discussion}

\subsection{Thermal Degradation of Treated LC Fiber}

The thermal degradation curve of chemically treated LC fiber obtained after alkali treatment, bleaching and acid hydrolysis is shown in Figure1.

Natural fibers are usually hydrophilic in nature and absorb a lot of moisture and the presence of moisture in the fibers leads to huge loss of mass in the temperature range of $150^{\circ} \mathrm{C}$. But when the $\mathrm{LC}$ fibers are treated with alkali, the hydrophilic nature is decreased due to removal of hemicellulose and lignin from the fiber. When the chemically treated LC fiber is heated up to $200^{\circ} \mathrm{C}$, there is only a marginal loss of mass of $2.37 \%$ shown as stage I in Figure 1. In the second stage (II) in the temperature range $250^{\circ} \mathrm{C}$ to $350^{\circ} \mathrm{C}$ a rapid loss of mass of around $55 \%$ is observed which can be due to degradation of amorphous cellulose present in the sample. In the third stage (III) beyond $350^{\circ} \mathrm{C}$ the degradation is due to decomposition of crystalline cellulose. There is a mass loss of $76 \%$ observed for treated LC fibers at $600^{\circ} \mathrm{C}$.

\subsection{Effect of Fiber Content on Thermal Profile of Composite Samples}

When chemically treated LC fibers were incorporated in to PLA matrix, considerable changes are expected to be observed in the thermal behavior of the composites. Figure 2 compares the derivative thermogravimetric (DTG) curves of sample B1, B2 and B3.The peaks of DTG curves in Figure 2 is due to decomposition of cellulose fibers in the composites. As evident from Figure 2, the DTG curve of treated fiber composites shifts towards right, i.e. towards higher temperature region with increase in fiber content in the composites. The cellulose degradation temperature was shifted from $335.61^{\circ} \mathrm{C}$ in sample $\mathrm{B} 1$ to $346.69^{\circ} \mathrm{C}$ in sample $\mathrm{B} 2$ and to $346.15^{\circ} \mathrm{C}$ in sample B3. The chemical treatment like alkali treatment followed by bleaching and acid hydrolysis on LC fiber exposed higher amount of celluloses on fiber surface. Higher amount of cellulose means higher number of reaction sites which lead to better and enhanced interlocking between treated LC fiber and PLA matrix. Due to the increased adhesion between treated LC fiber and matrix the cellulose degradation temperature probably shifted to higher side. But the lignin degradation temperature which is around $500^{\circ} \mathrm{C}$ was absent in the DTG curves indicating removal of lignin due to chemical treatment on LC fiber. It is worth mentioning that the difference in the shifting of peak is appreciable from sample $\mathrm{B} 1\left(335.61^{\circ} \mathrm{C}\right)$ to sample $\mathrm{B} 2\left(346.69^{\circ} \mathrm{C}\right)$. But the difference is minimal from sample B2 to sample B3 $\left(346.15^{\circ} \mathrm{C}\right)$.

Due to increase in hydrophobicity of treated LC fiber, the \% of moisture is reduced in the treated fiber composites. The \% of mass loss of all the composite samples in various temperature ranges are presented in Table 1.

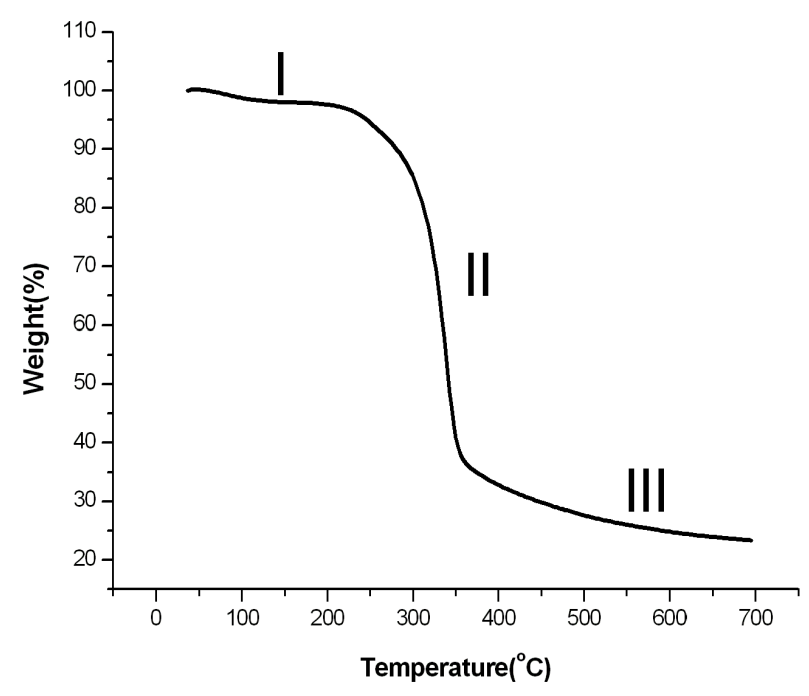

Figure 1. Thermal degradation curve of treated LC fiber (sample C). 


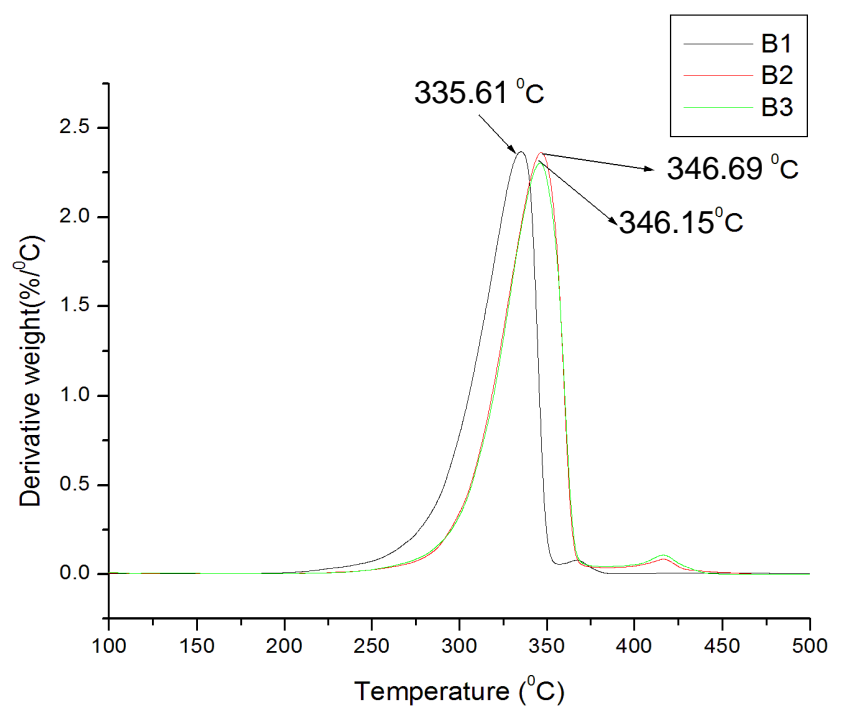

Figure 2. DTG curves for samples B1, B2 and B3.

Table 1. \% of mass loss of all the samples in different temperature ranges.

\begin{tabular}{ccccc}
\hline Sample & Loss of mass up to $100^{\circ} \mathrm{C}$ & Loss of mass up to $200^{\circ} \mathrm{C}$ & Loss of mass up to $300^{\circ} \mathrm{C}$ & Loss of mass up to $400^{\circ} \mathrm{C}$ \\
\hline C & 2.37 & 68 & 76 & 99.12 \\
B1 & 0.07 & 0.48 & 16.63 & 98.82 \\
B2 & 0.39 & 0.88 & 6.84 & 97.38 \\
B3 & 0.46 & 0.98 & 7.13 & 9 \\
\hline
\end{tabular}

Data in Table 1 betokens that the initial loss of mass up to $100^{\circ} \mathrm{C}$ due to presence of moisture is reduced from $2.37 \%$ in pure treated LC fiber (sample C) to only $0.07 \%$ in treated fiber composite sample B1 (2\% reinforcement), $0.39 \%$ in sample B2 (5\% reinforcement) and $0.46 \%$ in sample B3 (10\% reinforcement). The sample B1 shows highest thermal stability up to $100^{\circ} \mathrm{C}$ due to reduced loss of mass. Furthermore it can be observed from Table 1 that most of the degradation of the composite samples occurred between $300^{\circ} \mathrm{C}$ to $400^{\circ} \mathrm{C}$. This degradation can be attributed to decomposition of cellulose present in the LC fiber. A loss of $83 \%$ of mass was reported for sample B1 in this range while the corresponding values were $92 \%$ and $90 \%$ in sample B2 and B3 respectively.

As evident from the tabular data in Table 1, when treated LC fibers are reinforced in the matrix the thermal stability is enhanced maximum for composite sample B1 with $2 \mathrm{wt} \%$ reinforcement indicating better adhesion between treated LC fiber and matrix. When the wt of treated fiber in the matrix increased the thermal stability was slightly decreased as observed for sample B2 and sample B3.

\subsection{Effect of Fiber Content on Crystallization}

The results obtained from the analysis of DSC curves of composite samples B0, B1, B2 and B3 are presented in tabular form in Table 2.

Table 2 betokens that the crystallization temperature $\left(\mathrm{T}_{\mathrm{CC}}\right)$ of neat PLA (sample B0) was detected at $110.21^{\circ} \mathrm{C}$. The introduction of $2 \mathrm{wt} \%$ of $\mathrm{LC}$ fiber in to the matrix resulted increase of $\mathrm{T}_{\mathrm{CC}}$ to $115.21^{\circ} \mathrm{C}$ as in sample B1. But the value of $\mathrm{T}_{\mathrm{CC}}$ decreased for sample B2 \& B3 when more wt of LC fiber was added. This negative effect on crystallization for sample B2 \& B3 can be explained by suggesting more agglomeration of LC fibers in composite samples B2 and B3. The agglomeration of LC fibers can entrap PLA matrix \& actually restricted the crystallization of PLA. This is further confirmed by gradual decrease of crystallization enthalpy $\left(\Delta \mathrm{H}_{\mathrm{CC}}\right)$ with increase of fiber content (from $25.21 \mathrm{~J}$ in composite sample B1 to $22.12 \mathrm{~J}$ in composite sample B2 and $24.43 \mathrm{~J}$ in composite sample B3) shown in Table 2. With only $2 \mathrm{wt} \%$ of LC fiber in the composite sample B1, they are well dispersed in the PLA matrix. This well dispersion of LC fibers in sample B1 acts as nucleating 


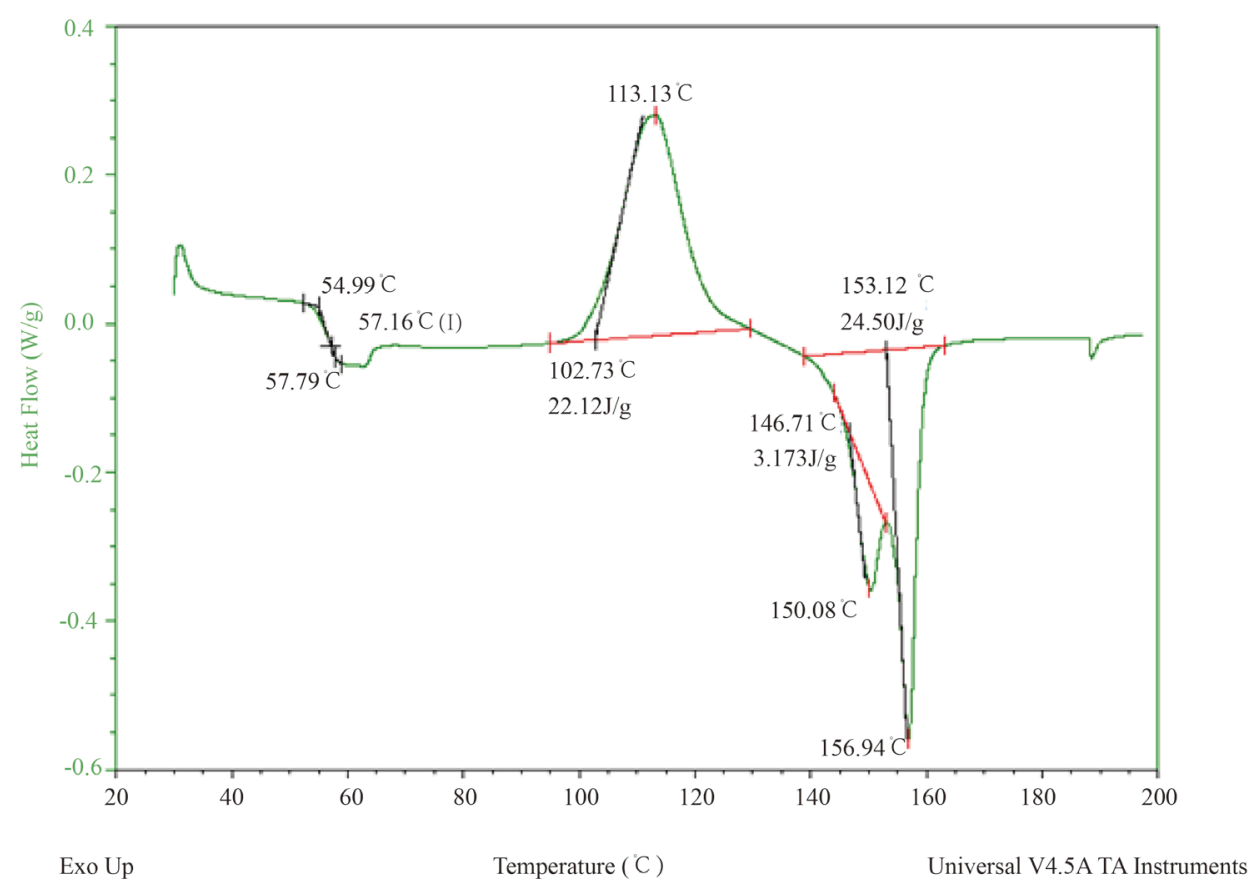

Figure 3. DSC thermograms of sample B3 (5 wt\% reinforcement).

Table 2. Values of glass transition temperature (Tg), Crystallization temperature (Tcc), crystallization enthalpy ( $\Delta$ Hcc), melting eak temperatures (Tm) and melting enthalpy (Hm) for composite samples B0, B1, B2 and B3.

\begin{tabular}{ccccccc}
\hline Sample & $\operatorname{Tg}\left({ }^{\circ} \mathrm{C}\right)$ & $\operatorname{Tcc}\left({ }^{\circ} \mathrm{C}\right)$ & $\Delta \operatorname{Hcc}(\mathrm{J})$ & $\operatorname{Tm} 1\left({ }^{\circ} \mathrm{C}\right)$ & $\operatorname{Tm} 2\left({ }^{\circ} \mathrm{C}\right)$ & $\operatorname{Hm}(\mathrm{J})$ \\
\hline B0 & 56.04 & 110.21 & 23.00 & 146.00 & 156.02 & 7.98 \\
B1 & 58.49 & 115.26 & 25.21 & 150.87 & 157.26 & 6.515 \\
B2 & 57.79 & 113.13 & 22.12 & 150.08 & 156.94 & 24.50 \\
B3 & 59.04 & 112.22 & 24.43 & 149.80 & 157.43 & 8.278 \\
\hline
\end{tabular}

sites. They promote the growth of PLA crystals by inducing more PLA chains to crystallize. However, with further increase in weight of fiber in sample $B_{2} \& B_{3}$, the crystal growth rate is decreased. In the study of polymers and their applications, it is important to understand the concept of the glass transition temperature, $T_{g}$. As the temperature of a polymer drops below $T_{g}$, it behaves in an increasingly brittle manner. As the temperature rises above the $T_{g}$, the polymer becomes more rubber-like. Thus, knowledge of $T_{g}$ is essential in the selection of materials for various applications. The glass transition temperature $\left(T_{g}\right)$ of neat PLA (samle B0) was recorded at $56.04^{\circ} \mathrm{C}$. However it shifted towards higher values in the composite samples B1, B2 and B3. When the LC fibers are loaded into the PLA matrix, the polymer molecules are immobilized at the interface. This may decrease the mobility of polymer molecules and hence the transition temperature shifts towards higher values. Figure 3 shows the DSC thermo grams of composite sample B3 (5 wt\%).

\subsection{Effect of Fiber Content on Double Melting Peak}

The multiple melting behavior is a common phenomena observed in DSC thermograms of polymorphic polymers. In case of PLA, this was detected as double melting peak. It arises from two crystalline structures of PLA i.e. $\alpha$ form or pseudo orthorhombic form and $\beta$ form or orthorhombic form. The " $\beta$ " form known as imperfect crystals melts at lower temperature while $\alpha$ from melts at higher temperature. The two melting peak for neat PLA are found to be $146^{\circ} \mathrm{C}$ and $153.6^{\circ} \mathrm{C}$ [9].

With the introduction of LC fiber at $2 \mathrm{wt} \%$ in sample B1, the peak of the lower melting temperature was increased by $4.87^{\circ} \mathrm{C}$ (Table 2). However the melting peak at high temperature was not significantly affected by introduction of LC fiber. But the melting peak at low temperature decreased with addition of more wt of LC fi- 
ber as observed in sample B2 and B3. Small or imperfect crystals more readily lead to re-arrangement and recrystallization during the heating process. This significant re-organisation of the crystal phase results in multiple melting behavior. The first melting peak is reversible peak \& it corresponds to formation of secondary crystals. The $2^{\text {nd }}$ peak is the irreversible melting peak, beyond which the solid melts completely.

\section{Conclusion}

The thermal stability is enhanced due to incorporation of treated LC fibers particularly with the reinforcement of $2 \mathrm{wt} \%$ LC fiber (sample B1). The analysis of thermal degradation and thermal decomposition temperature explains the molecular interactions between LC fiber and PLA matrix. The enhancement in thermal stability of composites with introduction of LC fiber as confirmed from TG and DSC analysis indicates favorable interactions between fiber and matrix. The incorporation of LC fiber promoted recrystallization and formation of imperfect crystals in PLA composites giving rise to double melting peaks in DSC thermo grams. The crystallization temperature and melting peak temperature were elevated by addition of fiber which restricted chain mobility of PLA molecules. The reinforcing LC fibers also caused a slight increase in glass transition temperature and the best result was achieved at $2 \mathrm{wt} \%$ reinforcement as in sample B1 (Table 2). The objective of this study was to transform the low priced, local agricultural waste LC fiber into a value based material by introducing the fiber in a bio degradable matrix, such as in this case, PLA is worth consideration. Also there is a possible cost reduction in the final material, with not much reduction of final properties even if a significant improvement cannot be obtained.

\section{Acknowledgements}

The authors thank Laboratory of Advanced Research in Polymeric Materials (LARPM), CIPET, Govt of India for providing facilities and equipments for making this study.

\section{References}

[1] Kalia, S., Dufresne, A., Cherian, B.M., Kaith, B.S., Avérous, L., Njuguna, J. and Nassiopoulos, E. (2011) Cellulose-Based Bio- and Nanocomposites: A Review. International Journal of Polymer Science, Article ID: 837875, 35 p. http://dx.doi.org/10.1155/2011/837875

[2] John, M.J. and Thomas, S. (2008) Biofibres and Biocomposites. Carbohydrate Polymers, 71, 343-364. http://dx.doi.org/10.1016/j.carbpol.2007.05.040

[3] Zenkiewicz, M., Richert, J. and Różański, A. (2010) Effect of Blow Moulding Ratio on Barrier Properties of Polylactide Nanocomposite Films. Polymer Testing, 29, 251-257. http://dx.doi.org/10.1016/j.polymertesting.2009.11.008

[4] Bhatia, A., Gupta, R., Bhattacharya, S. and Choi, H. (2010) Effect of Clay on Thermal, Mechanical and Gas Barrier Properties of Biodegradable Poly(lactic acid)/Poly(butylene succinate) (PLA/PBS) Nanocomposites. International Polymer Processing, 25, 5-14. http://dx.doi.org/10.3139/217.2214

[5] Mazali, I.O. and Alves, O.L. (2005) Morphosynthesis: High Fidelity Inorganic Replica of the Fibrous Network of Loofa Sponge. Annals of the Brazilian Academy of Sciences, 77, 25-31. http://dx.doi.org/10.1590/S0001-37652005000100003

[6] Abdulkhani, A., Hosseinzadeh, J., Ashori, A., Dadashi, S. and Takzare, Z. (2014) Preparation and Characterization of Modified Cellulose Nanofibers Reinforced Polylactic acid Nanocomposite. Polymer Testing, 35, 73-79. http://dx.doi.org/10.1016/j.polymertesting.2014.03.002

[7] Srebrenkoska, V., Gaceva, G.B. and Dimesk, D. (2014) Biocomposites Based on Polylactic Acid and Their Thermal Behavior after Recycling. Macedonian Journal of Chemistry and Chemical Engineering, 33, 277-285.

[8] Seong Ok Han, Mehdi Karevan, I. Na Sim, Md A. Bhuiyan, Young Hun Jang, Jonathan Ghaffar and Kyriaki Kalaitzido (2012) Understanding the Reinforcing Mechanisms in Kenaf Fiber/PLA and Kenaf Fiber/PP Composites: A Comparative Study. International Journal of Polymer Science, 2012, Article ID: 679252.

[9] Mustapa, I.R., Shanks, R.A. and Kong, I. (2013) Melting Behavior and Dynamic Mechanical Roperties of Poly Lactic Acid-Hemp nano Silica Composites. Asian Transactions on Basic and Applied Sciences, 3, 29-37. 